\title{
The Future of Digital Health: Meeting Report
}

\author{
Priya Kumar leuan Clay \\ Evidation Health Inc., San Mateo, CA, USA
}

\section{Keywords}

Digital health · Decentralized trials · Digital measures

\begin{abstract}
At the end of 2020, Karger's Digital Biomarkers, together with Evidation Health, produced a special issue entitled "The Future of Digital Health." This brief meeting report provides an overview of the expert panel and workshop that were held in early 2021 to explore key topics raised in the special issue.

(c) 2021 The Author(s)

Published by S. Karger AG, Basel
\end{abstract}

\section{Introduction}

Digital health tools are becoming increasingly embedded in all phases of clinical research [1]. As development of the field gathers pace, a special issue of Karger's Digital Biomarkers (Fig. 1; [2]), produced in partnership with Evidation Health, focused on 3 key themes critical to continued adoption and acceptance of digital health tools: the maturation and regulatory acceptance of existing capabilities, the further innovation of new capabilities, and workforce development. A series of in-depth discussions were also held to give an insider view of this research and to explore overarching themes raised in the special issue.

\section{Special Issue}

Concrete progress towards these goals was addressed across the papers selected. Headway towards the qualification of digital measures for real-world gait speed as outcomes in a range of conditions was presented by the Innovative Medicines Initiative-funded Mobilise-D project [3]. The Critical Path for Parkinson's Consortium presented updates towards their vision for a precompetitive, multistakeholder, regulatory framework to enable the development and acceptance of digital measures and other digital tools for Parkinson's disease [4]. The work of Beattie et al. [5] shared details on a new data platform for passive data collection in the homes of diverse cohorts of older adults. The authors also see this platform as a precompetitive asset in developing therapies.

Best practice, from the field of psychometrics, towards engaging patients directly in helping to develop "measures that matter" was also discussed [6]. Research on advancements in making real-world step detection more flexible showed how algorithmic improvements can give patients more flexibility in terms of how they wear a device without compromising accuracy [7]. The potential of wearable devices to assess highly patient-relevant fatigue symptoms [8], or to predict long-term rehabilitation outcomes from consumer-grade data streams [9] further un-
C 2021 The Author(s)

Published by S. Karger AG, Basel

This is an Open Access article licensed under the Creative Commons Attribution-NonCommercial-4.0 International License (CC BY-NC) (http://www.karger.com/Services/OpenAccessLicense), applicable to the online version of the article only. Usage and distribution for commercial purposes requires written permission.
Correspondence to:

Ieuan Clay, iclay@evidation.com 


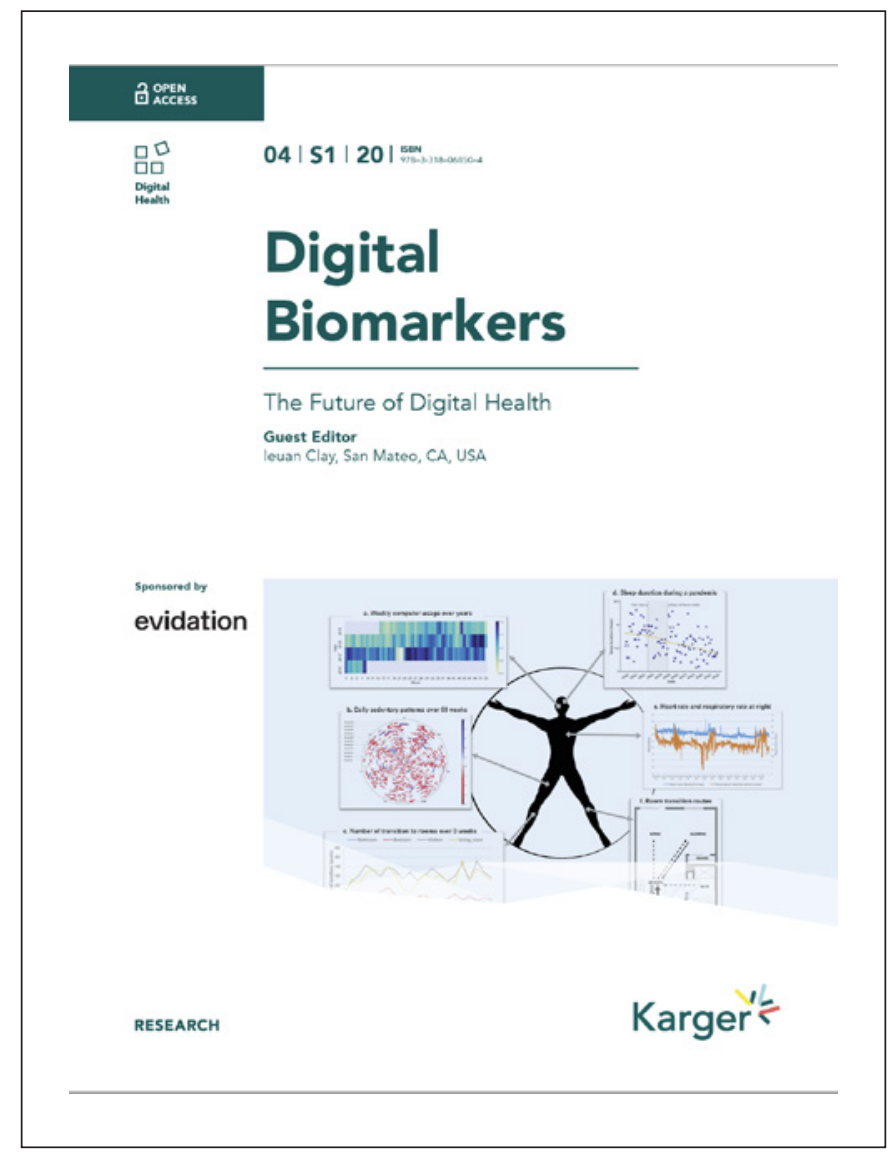

Fig. 1. Karger Digital Biomarkers special issue "The Future of Digital Health".

derlined the importance of digital measures for making evidence generation even more effective.

A qualitative study from Keogh et al. [10] described how this evidence can be most effectively communicated to clinicians. The emerging role of "digital navigators" [11] showed one approach to bringing digital health technologies into clinical care, and Goldsack and Zanetti [12] expanded on this theme to discuss how digital health technologies are demanding and driving broader workforce development.

\section{The Expert Panel}

In late January 2021, Evidation Health and Karger Publishers cohosted a comprehensive discussion (available online [13]). Experts from across the healthcare ecosystem discussed what the future holds and how current advancements in digital measures will be the buildingblocks for a digitally enabled, patient-centric healthcare transformation. Panelists included Diane Stephenson, executive director of Critical Path for Parkinson's at the Critical Path Institute, Mikki Nasch, cofounder and VP of Business Development at Evidation Health, Ray Dorsey, the editor of Digital Biomarkers (and Professor of Neurology and Director of the Center of Health + Technology at the University of Rochester, Rochester, NY, USA), and Ronenn Roubenoff, the global head of Translational Medicine Discovery and Profiling at Novartis.

The panelists discussed the biggest challenges across the healthcare ecosystem, the opportunities that digital solutions create to address the industry's most critical challenges, and the imperatives for the industry to make meaningful progress towards this vision of the future of health. The panel endorsed the statement that the "future" of digital health is already here. Amidst the COVID-19 pandemic, the industry is seeing a sense of urgency and response from both patients and doctors to incorporate digital health opportunities in day-to-day health. As a practicing neurologist, Dorsey mentioned the uptake in patients wanting to undergo telemedicine during the pandemic to help manage their conditions. Roubenoff raised the point that, currently, sponsors go to doctors to find patients for their studies. With the next generation of clinical trials, sponsors can go directly to the patient. This requires a change in mindset, i.e., that industry designs studies that address the needs of participants, not the needs of investigators and sites. Launched in 2011, the "REMOTE" trial from Pfizer (ClinTrials.gov ID: NCT01302938) started the shift towards non-sitebased trials [14]. Since then, the scale and ambition of such trials has ever increased, e.g., the Heartline Study, by Johnson \& Johnson, launched in 2020 (ClinTrials.gov ID: NCT04276441). The explosion in companies supporting part, or all, of the capabilities required to enable participants to engage in research on their own terms serves to underline that this "next generation" is already here [15].

Stephenson spoke about the importance of incorporating patient centricity in clinical development and the notion of whether digital measures are a precompetitive tool or a competitive advantage. Much of the work in the special issue was done by, or was directly supported by, precompetitive consortia supporting the value of these projects $[3,4]$. By incorporating person-generated health data into core business operations, we can understand daily patient burden as a function to force the development of better interventions [16].

The group also discussed the need to engage with regulators (and payers) on the acceptance of digital measures as evidence, and how it is important to consider multiple 
applications of digital health technology beyond digital measures, including precision medicine, identifying and recruiting at-risk individuals, and enhancing decisionmaking in advancing promising targets. Person-generated health data are a good indicator of an individual's health and disease progression.

The discussion concluded with a vision for the future: "What steps can the industry take to realize that we are currently living in the future and this is how we can grow the industry and help individuals improve their health?"

Nasch spoke about the need to increase health engagement and patient activation, and the importance of understanding an individual's everyday life outside of the healthcare setting. The group also discussed how capturing payer-relevant evidence earlier can have a positive impact, and how we need to continue to incorporate RWE and RWD, predictive analytics, and other datadriven approaches. Stakeholders need to continue to acknowledge the power of digital measures to help us better understand an individual's health conditions and daily life, but also the role that such tools can play in activating patients, e.g., helping individuals to engage with their own health.

\section{Discussion}

Overall, the group of experts had much to say about the positive impact of digital measures on both the pharmaceutical industry and patient-provider relationships.

Perhaps the next step for the field will be to move beyond thinking of digital measures simply in terms of generating evidence, but rather as a tool for activating patients. This might happen by helping individuals engage with their health (as seen in the above mentioned Heart- line Study) or by overcoming barriers to navigating health systems [17]. As we start to understand better how patients engage with such tools [18], a further interesting development would be the use of digital measures to aid the personalization of each individual's experience.

The Karger Digital Biomarkers Evidation Health fireside chat is available online [13], or one can visit Karger's Special Issue website [19] which also contains short introductions to all the papers by the authors themselves. A workshop, cohosted with the Digital Medicine Society [20], is also available online [21].

\section{Acknowledgement}

We are extremely grateful to the authors who submitted their work to the special issue, the panelists and participants in the workshop and fireside chat, Evidation Health for their guidance and sponsorship, the Digital Medicine Society for cohosting the workshop, and, of course, the leadership and team at Karger. Without all of you, this special issue would not have been so special.

\section{Conflict of Interest Statement}

The special issue was sponsored by Evidation Health Inc. Both authors are employees of Evidation Health Inc.

\section{Funding Sources}

This work was entirely self-funded.

\section{Author Contributions}

P.K. and I.C. conceived and designed the article concept, drafted the article, and are responsible for final approval of the version to be published.

\section{References}

1 Marra C, Chen JL, Coravos A, Stern AD. Quantifying the use of connected digital products in clinical research. NPJ Digit Med. 2020 Apr;3(1):50.

2 Clay I. The Future of Digital Health. Digit Biomark. 2020 Nov;4 Suppl 1:1-2.

3 Rochester L, Mazzà C, Mueller A, Caulfield B, McCarthy M, Becker C, et al. A Roadmap to Inform Development, Validation and Approval of Digital Mobility Outcomes: The Mobilise-D Approach. Digit Biomark. 2020 Nov;4 Suppl 1:13-27.
4 Stephenson D, Alexander R, Aggarwal V, Badawy R, Bain L, Bhatnagar R, et al. Precompetitive Consensus Building to Facilitate the Use of Digital Health Technologies to Support Parkinson Disease Drug Development through Regulatory Science. Digit Biomark. 2020 Nov;4 Suppl 1:28-49.

5 Beattie Z, Miller LM, Almirola C, Au-Yeung WM, Bernard H, Cosgrove KE, et al. The Collaborative Aging Research Using Technology Initiative: An Open, Sharable, TechnologyAgnostic Platform for the Research Community. Digit Biomark. 2020 Nov; 4 Suppl 1:10018.
6 Houts CR, Patrick-Lake B, Clay I, Wirth RJ The Path Forward for Digital Measures: Suppressing the Desire to Compare Apples and Pineapples. Digit Biomark. 2020 Nov; 4 Suppl $1: 3-12$.

7 Tietsch M, Muaremi A, Clay I, Kluge F, Hoefling H, Ullrich M, et al. Robust Step Detection from Different Waist-Worn Sensor Positions: Implications for Clinical Studies. Digit Biomark. 2020 Nov;4 Suppl 1:50-8.

8 Luo H, Lee PA, Clay I, Jaggi M, De Luca V. Assessment of Fatigue Using Wearable Sensors: A Pilot Study. Digit Biomark. 2020 Nov; 4 Suppl 1:59-72. 
9 Karas M, Marinsek N, Goldhahn J, Foschini L, Ramirez E, Clay I. Predicting Subjective Recovery from Lower Limb Surgery Using Consumer Wearables. Digit Biomark. 2020 Nov;4 Suppl 1:73-86.

10 Keogh A, Johnston W, Ashton M, Sett N, Mullan R, Donnelly S, et al. “It's Not as Simple as Just Looking at One Chart": A Qualitative Study Exploring Clinician's Opinions on Various Visualisation Strategies to Represent Longitudinal Actigraphy Data. Digit Biomark. 2020 Nov; 4 Suppl 1:87-99.

11 Wisniewski H, Gorrindo T, Rauseo-Ricupero N, Hilty D, Torous J. The Role of Digital Navigators in Promoting Clinical Care and Technology Integration into Practice. Digit Biomark. 2020 Nov; 4 Suppl 1:119-35.

12 Goldsack JC, Zanetti CA. Defining and Developing the Workforce Needed for Success in the Digital Era of Medicine. Digit Biomark. 2020 Nov;4 Suppl 1:136-42.
13 The Future of Digital Health [cited 2021 Feb 1]. Available from: https://www.youtube. $\mathrm{com} /$ watch? $\mathrm{v}=\mathrm{BDdImaX3i9o}$.

14 Ledford H. [Internet] "Virtual" trial brings clinical research home: news blog. [cited 2021 Feb 11]. Available from: http://blogs.nature. com/news/2011/06/virtual_clinical_trial_ could_h_1.html.

15 Coravos A. Software-Enabled Clinical Trials - Andrea's Blog [Internet]. Andrea's Blog. 2017 Sep [cited $2021 \mathrm{Feb} 11$ ]. Available from: https://blog.andreacoravos.com/softwareenabled-clinical-trials-8da53f4cd271.

16 Izmailova ES, Wagner JA, Ammour $\mathrm{N}$, Amondikar N, Bell-Vlasov A, Berman S, et al. Remote Digital Monitoring for Medical Product Development. Clin Transl Sci. 2020 Aug; 3:55.
17 Griese L, Berens EM, Nowak P, Pelikan JM, Schaeffer D. Challenges in Navigating the Health Care System: Development of an Instrument Measuring Navigation Health Literacy. Int J Environ Res Public Health. 2020 Aug;17(16):E5731.

18 Chien I, Enrique A, Palacios J, Regan T, Keegan D, Carter D, et al. A Machine Learning Approach to Understanding Patterns of Engagement With Internet-Delivered Mental Health Interventions. JAMA Netw Open. 2020 Jul;3(7):e2010791.

19 Karger Special Issue [Internet]. [cited 2021 Feb 1]. Available from: https://pages.evidation.com/karger-special-issue https://doi. org/10.1001/jamanetworkopen.2020.10791.

20 Home - Digital Medicine Society (DiMe) [Internet]. [cited $2021 \mathrm{Feb} 5$ ]. Available from: https://www.dimesociety.org/.

21 The Future of Digital Health. 2020 [cited 2021 Feb 1]. Available from: https://www.youtube. com/watch?v=E74PiCg1vI8. 